\title{
The predictive capacity of the high resolution weather research and forecasting model: a year-long verification over Italy
}

\author{
L. Apicella ${ }^{1,2} \cdot$ S. Puca ${ }^{3} \cdot$ M. Lagasio ${ }^{2} \cdot$ A. N. Meroni ${ }^{2,4} \cdot$ M. Milelli ${ }^{2,5} \cdot$ N. Vela $^{5}$. \\ V. Garbero ${ }^{5} \cdot$ L. Ferraris ${ }^{2} \cdot$ A. Parodi Pa $^{2,6}$
}

Received: 2 July 2020 / Accepted: 21 February 2021 / Published online: 7 April 2021

(C) The Author(s) 2021

\begin{abstract}
Numerical models are operationally used for weather forecasting activities to reduce the risks of several hydro-meteorological disasters. The overarching goal of this work is to evaluate the Weather Research and Forecasting (WRF) model predictive capabilities over the Italian national territory in the year 2018, in two specific cloud resolving configurations. The validation is carried out with a fuzzy logic approach, by comparing the precipitation predicted by the WRF model, and the precipitation observed by the national network. The fuzzy logic technique, by considering different intensity thresholds, allows to identify the reliable spatial scales of the forecasts. The same approach is applied to evaluate the performances of COSMO-2I model, a state-of-the-art numerical model configuration used for operational activities. For the entire year, except for summer, the model predictive capabilities are high, with useful forecasts for structures of medium intensities down to $O(10 \mathrm{~km})$ length scales. In summer the skills decrease mainly because of localization errors. The work aims to provide a robust evaluation of the forecast performances of another convection permitting operational meteorological models currently available in Italy.
\end{abstract}

Keywords Weather research and forecasting · WRF · Italy · Weather data validation . Precipitation · Fuzzy logic

\section{Introduction}

Numerical weather prediction (NWP) represents a fundamental component of the Civil Protection system and aims to forecast the triggering factors of most natural disasters. In this way, the monitoring phase of the weather and ground-related phenomena, and the alert phase of the different Civil Protection system actors can be timely activated (Ferraris et al. 2002). However, NWP role is not limited to the forecasting phase, but it becomes even more

A. Parodi

antonio.parodi@cimafoundation.org

Extended author information available on the last page of the article. 
relevant during the emergency management, especially when the meteorological phenomena represent the main ingredients and forcing (Llasat et al. 2010a). In this phase, NWP is important to quantify the human and technical resources needed to manage the event spatiotemporal evolution, and its hydro-meteorological impacts. Finally, NWP is very important in determining if and when a given hydro-meteorological emergency phase can be closed.

The possible occurrence of a meteorological hazard is usually represented by the probability of overcoming some thresholds (rain depth, snow depth, temperature). Such thresholds are defined on the basis of the analysis of historical records for meteorological events leading to severe ground effects over a given area (Reichenbach et al. 1998; Peruccacci et al. 2017). Nowadays, the joint use of models, observational data, interpretative experience and a good ability to timely give the relevant information to the decision maker allow weather forecasts to reach very high reliability standards. This is absolutely relevant for Civil Protection purposes from a cost-benefit point of view.

The Mediterranean area is one of the world most exposed territories to the occurrence of meteorological hazards (Llasat et al. 2010b). In particular, the main risks are associated with extreme precipitation events impacting complex orography and densely urbanized areas, often leading to floods and flash-floods, landslides, infrastructure damages and agricultural losses, as well as casualties. Italy, as part of the Mediterranean area, is a climate change hotspot, meaning that the potential impacts of climate change are expected to be particularly pronounced in its territory (Giorgi 2006). In this respect, the availability of cloud-resolving NWP capabilities at the national and regional level is a matter of great importance.

Nowadays, different cloud-resolving NWP models are available in Italy as reported briefly hereafter. ARPA Emilia-Romagna (the Regional Agency for Environmental Protection of Emilia-Romagna), the Italian Air Force and ARPA Piemonte (the Regional Agency for Environmental Protection of Piedmont) operate the COnsortium for Small-scale MOdeling (Baldauf et al. 2011, COSMO). LAMMA (Environmental Modelling and Monitoring Laboratory for Sustainable Development) operates the Weather Research and Forecasting (Skamarock et al. 2008, WRF) model at $3 \mathrm{~km}$ grid-spacing (Capecchi and Buizza 2019) and the MOdello LOCale (Tettamanti et al., 2002; Malguzzi et al., 2006; Trini Castelli et al., 2020; Buzzi et al., 2014, MOLOCH) model at $2.5 \mathrm{~km}$ over Italy using both ECMWF-IFS (European Center for Medium-Range Weather Forecasts-Integrated Forecasting System) and NCEP-GFS (National Center for Environmental Protection-Global Forecasting System) initial and boundary conditions data. ISAC-CNR develops and operates the MOLOCH model at $1.25 \mathrm{~km}$ grid-spacing over Italy using NCEP-GFS analysis as initial condition and GLOBO model forecasts as boundary conditions (Malguzzi et al. 2011). MOLOCH is also operated at ISPRA (Higher Institute for Environmental Protection and Research), as part of the Hydro-Meteo-Marine forecasting System (SIMM) at $2.5 \mathrm{~km}$ grid-spacing (Mariani et al. 2015), and at ARPA Liguria (since, roughly, the early 2000s) at $1.5 \mathrm{~km}$. Operational forecasting activities are also ongoing at CETEMPS (Center of Excellence Telesensing of Environment and Model Prediction of Severe events), where WRF is run at up to $1 \mathrm{~km}$ horizontal grid-spacing.

CIMA Research Foundation (CIMA, hereafter) has a significant experience in using the WRF model for hydro-meteorological research applications in tropical and subtropical areas (Parodi and Tanelli 2010; Marras et al. 2017; Viterbo et al. 2016), and for mid-latitude severe weather studies (Parodi et al. 2012; Fiori et al. 2014; Viterbo et al. 2016; Fiori et al. 2017; Lagasio et al. 2017; Parodi et al. 2019; Silvestro et al. 2019; Meroni et al. 2018). Recently, a solid know-how on Data Assimilation (DA) simulations for high impact weather events has been developed, as well. In particular, the WRFDA software (Barker et al. 2012) 
has been exploited, using cutting edge observations and techniques. For example, a new operator for the assimilation of radar data was developed by Lagasio et al. (2019c), or high resolution satellite-derived maps were assimilated by Lagasio et al. (2019b) and Lagasio et al. (2019a), showing a positive impact on the forecast of heavy rainfall events in Italy. CIMA is also actively involved in research activities about the impacts that the assimilation of high resolution water vapor maps has on the forecast of heavy rains (Meroni et al. 2020). These activities also contribute to the development of a future geosynchronous SAR (Synthetic Aperture Radar) satellite mission (Ruiz Rodon et al. 2013; Monti Guarnieri and Rocca 2017; Monti Guarnieri et al. 2018; Lagasio et al. 2020), which would provide unprecedented observations of the water cycle on Earth. Starting from 2018 CIMA has provided the outputs of two WRF modelling setups to ARPA Liguria (the Regional Agency for Environmental Protection of Liguria) and to the Italian Civil Protection Department for operational purposes, in particular an open loop setup covering the entire country (see next section for the details), and a setup with DA covering the northern part of Italy (not shown).

The overarching goal of this work is to evaluate the predictive capability of the WRF model operated by CIMA at $1.5 \mathrm{~km}$ horizontal grid-spacing over the Italian peninsula during the year 2018, with a focus on precipitation. Its performances are compared with a state-of-the-art operational configuration of the COSMO model, operated by ARPA Emilia Romagna at roughly $2.8 \mathrm{~km}$ grid-spacing (ARPAE 2020). The validation counterpart are the rainfall observational data obtained by the merging of rain gauge measurements and meteorological radar rainfall estimates. Statistics concerning this comparison are presented through a series of indices (POD, FAR, FSS) based on a fuzzy logic approach (Ebert 2008).

The verification of numerical models is highly demanded, especially for civil protection applications. This work provides the first predictive capability assessment and model comparison between WRF and COSMO models at convection permitting scales. A similar work was carried out by Oberto et al. (2012), who compared COSMO-I7 and WRF-NMM (Nonhydrostatic Mesoscale Model) for 2007 and 2008 on the Italian territory. They compared the model outputs with a grid-spacing of $7 \mathrm{~km}$, showing that the two models have comparable biases on different precipitation intensities.

This paper is structured in the following way: Section 2 describes the numerical model setups, the observational data sets and the verification method. Results are presented in Section 3, while discussions and conclusions are given in Section 4.

\section{Data and methods}

\subsection{Model configurations}

The WRF model is an open source code conceived and developed since the mid 90's by NCAR (National Center for Atmospheric Research), NOAA (National Oceanic and Atmospheric Administration), U.S. Air Force, Naval Research Laboratory, University of Oklahoma, and the Federal Aviation Administration. WRF is a mesoscale forecasting system that solves the non hydrostatic fully compressible Euler equations on an Arakawa-C grid with mass-based terrain following coordinates. It is designed for both research and operational applications, capable of operating at spatial resolutions from hundreds of meters to hundreds of kilometers (Powers et al. 2017).

This work focuses on an operational setup currently running at CIMA on behalf of the Italian Civil Protection Department, namely the WRF-OL configuration. It is the Open Loop (OL) configuration without data assimilation. It has three two-way nested domains with 


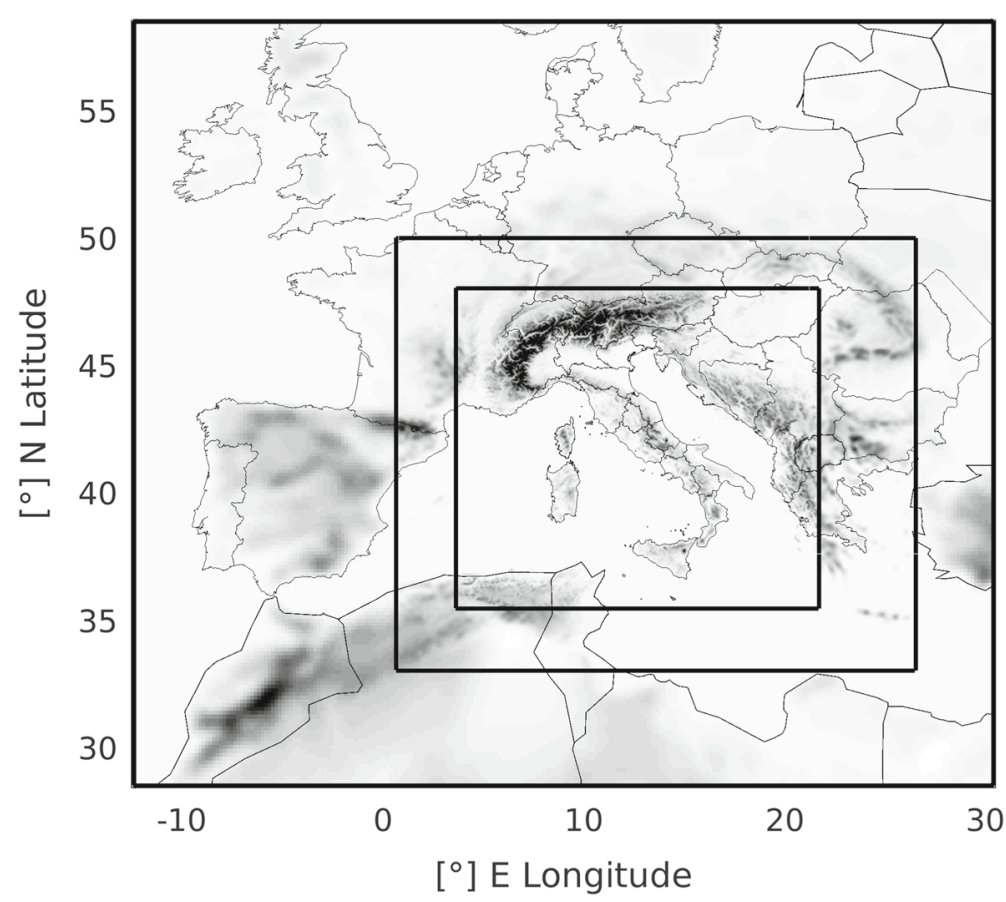

Fig. 1 Domain configuration of WRF-OL with horizontal grid-spacing of $13.5,4.5$ and $1.5 \mathrm{~km}$ and 50 vertical levels

13.5, 4.5, and $1.5 \mathrm{~km}$ grid-spacing and with 50 vertical levels (Fig. 1). The innermost domain grid is composed of $943 \times 883$ points. Initial and hourly boundary conditions are taken from the NCEP-GFS with $0.25^{\circ}$ grid-spacing. The model runs a 48 hours forecast every day, starting from 00 UTC.

WRF-OL is configured with the following physical parameterizations. The Yonsei University scheme (Hong et al. 2006) is chosen for the planetary boundary layer turbulence closure; the RRTMG shortwave and longwave schemes (Iacono et al. 2008; Mlawer et al. 1997; Iacono et al. 2000) are used for radiation; and the Rapid Update Cycle (RUC) scheme is chosen as a multi-level soil model (6 levels) with higher resolution in the upper soil layer $(0,5,20,40,160,300 \mathrm{~cm})$ (Smirnova et al. 1997; Smirnova et al. 2000). For consistency with the GFS initial and boundary conditions, the New Simplified Arakawa-Schubert scheme (Han and Pan 2011) is used with the following distinct approaches. No cumulus scheme is activated in the two innermost domains ( 4.5 and $1.5 \mathrm{~km}$ grid-spacing), because the grid-spacing enables to resolve the convection dynamics, while it is activated in the outermost domain (13.5 km grid-spacing).

In the present work, a comparison between WRF-OL and COSMO-2I (ARPAE 2020) is performed. The COSMO-2I domain covers the entire Italian territory, the boundaries conditions are provided by COSMO 5M, which is nested in the ECMWF-IFS global model at $0.125^{\circ}$ grid-spacing, while initial conditions are provided by the high resolution KENDALETKF deterministic analysis (Schraff et al. 2016). The grid is setup with $2.8 \mathrm{~km}$ horizontal grid-spacing and 65 vertical levels. Forty-eight-hour forecasts are provided with two daily 
runs at 00 and 12 UTC. All details on the setup of the COSMO-2I and COSMO 5M models can be found at ARPAE (2020).

\subsection{Data description}

This work aims to evaluate the WRF-OL precipitation predictive capability by comparing the quantitative precipitation forecast (QPF) fields obtained from the model runs with the observational quantitative precipitation estimates (QPEs).

QPF fields are directly obtained from the model outputs on their native grid. Since WRF forecasts are 48 hours long we will refer to RUN1 as the first 24 hours of the forecast and as RUN2 for the subsequent 24 hours.

Two observational rainfall datasets are considered: the ground-based meteorological station networks and the Italian Radar Network (IRN), both managed by the Italian Civil Protection Department. In particular, the ground-based sensors, that are thermometers, rain gauges, hygrometers and anemometers, belong to two networks: the Functional Centers Network (FCN) and Public Administrations Unique Network (PAUN). In total, there are 5222 ground-based sensors, among which 3551 are from PAUN and 4881 are from FCN (some stations belong to both networks). They have been collecting data since 2004 and 2006, respectively. Data from 4366 rain gauges from the two ground-based networks are used in the present work.

Radar data come from the IRN mosaic operated by the Italian Civil Protection (Vulpiani et al. 2008), that covers the whole Italian territory. In particular, hourly SRT (Surface Rainfall Total) maps are obtained opportunely summing the SRI (Surface Rainfall Intensity) maps, provided every 10 minutes.

The QPEs used in this study are obtained by merging the ground based precipitation data provided by both aforementioned rain gauges networks (stations belonging to both networks are counted only once) together with SRT maps from the IRN mosaic. The merging is performed with the Rainfusion method (Pignone et al. 2013; Sinclair and Pegram 2005; Silvestro et al. 2016) producing hourly maps at $1.5 \mathrm{~km} \times 1.5 \mathrm{~km}$ horizontal resolution.

\subsection{Fuzzy logic analysis}

A fuzzy logic analysis allows a comparison between observed and forecast data, with the advantage that the final error is not calculated pointwise, but allowing a spatial window in which the comparison is performed (Ebert 2008). In this study, we exploit the anywherein-the-window fuzzy logic approach, as described by Ebert (2008). This is a special case of "minimum coverage" technique, which is an example of Neighbourhood ObservationNeighbourhood Forecast strategy. Ten thresholds of precipitation intensities, namely, 0.1, $0.2,0.5,1,2.5,5,7.5,10,12$ and $15 \mathrm{~mm} / 3 \mathrm{~h}$ are considered and the agreement between QPE and QPF is evaluated starting from a single COSMO-2I pixel $(2.8 \mathrm{~km} \times 2.8 \mathrm{~km}=$ $\left.7.84 \mathrm{~km}^{2}\right)$ up to squares with 65 pixels per side $\left(182 \mathrm{~km} \times 182 \mathrm{~km} \simeq 33000 \mathrm{~km}^{2}\right)$. The COSMO-2I grid is chosen as the common grid for the validation (for both modelled and observational products), because it is the coarsest. Remind that, in the fuzzy logic approach, an event is defined when the rainfall intensity (either observed or predicted) overcomes the given threshold (Ebert 2008). Three scores are calculated: the Fractions Skill Score (FSS), the Probability Of Detection (POD), and the False Alarm Ratio (FAR) (Ebert 2008).

The FSS is the main index summarizing the potential of a fuzzy logic verification. It directly compares the forecast and observation fields on a certain area affected by an event (defined when the precipitation exceeds a certain threshold in the unit time), gradually 
increasing the spatial dimension of the box on which the verification is carried out. It is given by

$$
\mathrm{FSS}=1-\frac{\frac{1}{N} \sum_{i=1}^{N}\left(P_{\mathrm{fcs}}-P_{\mathrm{obs}}\right)^{2}}{\frac{1}{N} \sum_{i=1}^{N} P_{\mathrm{fcs}}^{2}+\frac{1}{N} \sum_{i=1}^{N} P_{\mathrm{obs}}^{2}},
$$

where $N$ is the number of verification boxes in the domain under study and $P$ is the fraction of each single box in which the event occurs (the subscripts fcs and obs stand for "forecast" and "observed", respectively). The FSS ranges from 0 (complete disagreement) to 1 (perfect agreement). The FSS is equal to 0 if there are no expected events but they do occur or, vice versa, if no events that have been foreseen occur. The FSS value above which the forecast is considered useful (better than the random data) is given by $\mathrm{FSS}_{\text {useful }}=0.5+f_{0} / 2$, where $f_{0}$ is the fraction of the domain covered by the observed event (Roberts and Lean 2008). The smallest spatial window for which FSS $\geq \mathrm{FSS}_{\text {useful }}$ is considered to be the useful scale. As the dimensions of the spatial windows increase, the index tends asymptotically to a value between 0 and 1 . The closer this value is to 1 , the less the forecast is biased. The FSS is sensitive to rare events, which are intense precipitation peaks on limited areas.

The POD is the ratio of the correctly forecast events and the events that actually occurred (range: $0-1$, perfect value: 1 ), namely

$$
\mathrm{POD}=\frac{\text { hits }}{\text { hits }+ \text { misses }} .
$$

The FAR is the proportion of forecasts of the event that did not occur (range: $0-1$, perfect value: 0$)$. It is calculated as

$$
\mathrm{FAR}=\frac{\text { false alarms }}{\text { hits }+ \text { false alarms }}
$$

and it measures the probability of false detection. For both POD and FAR computation, contingency tables are considered following the 'minimum coverage' technique introduced above, for different box dimensions and rainfall intensity thresholds.

These three scores have different meanings: the FSS measures how the skill of precipitation forecasts varies with spatial scale (Roberts and Lean 2008); POD and FAR indicate, respectively, the probability of detection of a certain kind of event and the rate at which it is likely to forecast an event which actually does not occur.

This analysis is carried out with three-hourly QPE and QPF in the period between March 2018 and February 2019, on a seasonal basis, following the conventional definitions of: spring MAM, summer JJA, fall SON and winter DJF. Considering seasons instead of months enables to have larger numbers of events and, thus, robust statistics. The whole Italian territory is considered, producing charts with the performances of the first 24 hours (RUN1) and second 24 hours (RUN2) of the forecasts in terms of FSS, POD and FAR. Both QPE and QPF are interpolated on the COSMO-2I grid at $0.025^{\circ}$ (roughly $2.8 \mathrm{~km}$ ), excluding the sea, as discussed above.

\section{Results}

From an operational forecast user perspective, fuzzy verification gives important information on the scales and intensities at which the forecasts should be trusted. The analysis of the FSS, FAR and POD scores on a seasonal basis provides a deep insight on the model predictive capability for the QPF field: a good QPF performance corresponds to high values of FSS, high POD values and low FAR values. In particular, the FSS, FAR and POD indices 
a

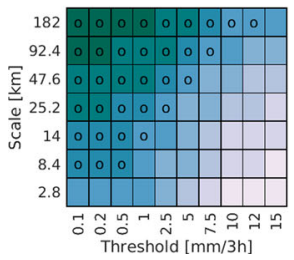

b

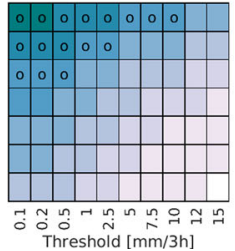

C

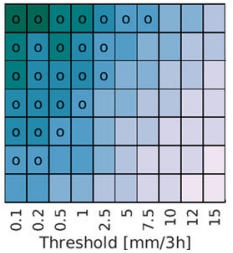

d

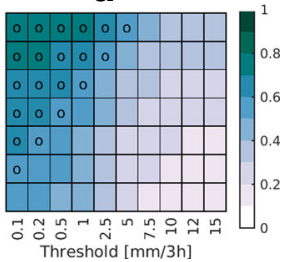

Fig. 2 Seasonal FSS scores for WRF-OL RUN1. Empty circles denote useful FSS values

are shown as functions of precipitation threshold (abscissas) and spatial scale (ordinates), namely the dimension of the side of the verification box. For example, by looking at the lower right corner of these charts, it is possible to assess the model performances for events characterized by small spatial scales and high intensity, that are of primary importance for civil protection purposes.

\subsection{A fuzzy logic year-long comparison between WRF-OL and COSMO-2I}

Figures 2 and 3 show the RUN1 FSS indices for WRF-OL and COSMO-2I, indicating that the performances of the two models are comparable. A distinct seasonal behaviour is visible in both figures, with useful forecast covering a wider range of spatial scale and threshold combinations in spring, autumn and winter.

More in detail, consider the following classes of rainfall: light rain for intensities lower than $1.5 \mathrm{~mm} / 3 \mathrm{~h}$; moderate rain between 1.5 and $12 \mathrm{~mm} / 3 \mathrm{~h}$; and heavy rain higher than $12 \mathrm{~mm} / 3 \mathrm{~h}$ (UK Met Office 2102). For light rain, the spatial scale at which the forecast is reliable is of the order of $10 \mathrm{~km}$ in spring, $50 \mathrm{~km}$ in summer, $15 \mathrm{~km}$ in fall and roughly $20 \mathrm{~km}$ in winter. For heavy rain, instead, the reliable spatial scale is of the order of $200 \mathrm{~km}$ or higher (especially in summer, when no reliable scales is found for WRF-OL, and in winter, for both models). Within the range of moderate rainfall intensities, the reliable spatial scale,

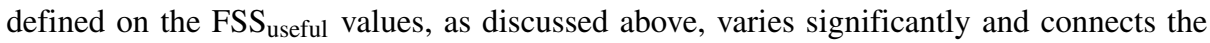
light and the heavy rainfall values.

On the one hand, the most noticeable difference between WRF-OL and COSMO-2I concerns the heavy rainfall intensities. In particular, it generally appears that WRF-OL is statistically less reliable than COSMO-2I. However, the usefulness of a forecast on scales of the order of $200 \mathrm{~km}$, reached by COSMO-2I, is also questionable. On the other hand, WRF-OL shows better performances during winter, for both light and moderate rainfall intensities.

a

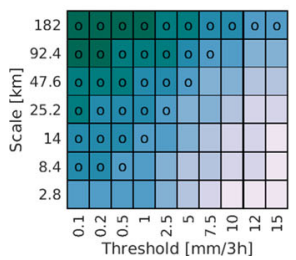

b

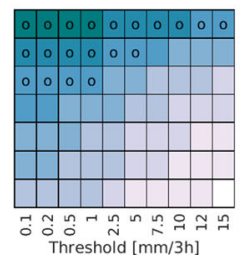

C

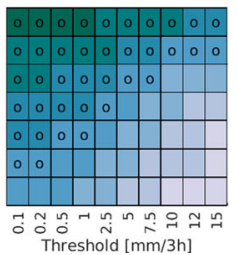

d

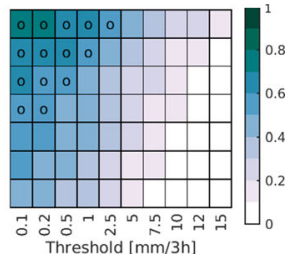

Fig. 3 Seasonal FSS scores for COSMO-2I RUN1. Empty circles denote useful FSS values 
a

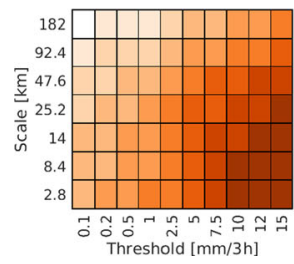

b

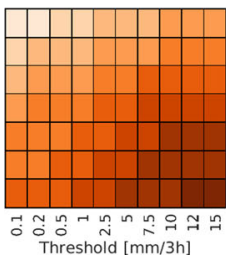

C

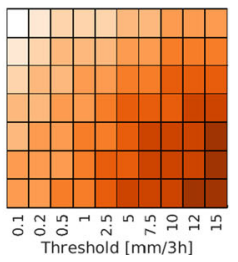

d

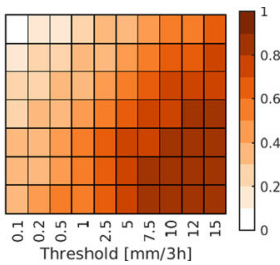

Fig. 4 Seasonal FAR scores for WRF-OL RUN1

Considering the WRF-OL configuration, the fact that the seasonal FSS skill variations are particularly strong for the low precipitation accumulation thresholds can be interpreted in another way. The fact that the set of useful combinations of spatial scales and thresholds intensities visibly decreases in summer by shrinking in the upper part of the chart means that the performances at high precipitation threshold do not change much over the course of the year. From a forecaster point of view, thus, it becomes more difficult to predict the location of the precipitation event, independently of its intensity. For COSMO-2I, an additional performance degradation is visible in winter.

To interpret the FSS skill behaviour, it is insightful to look at the FAR and POD indices, shown in Figs. 4 and 6 for WRF-OL and in Figs. 5 and 7 for COSMO-2I, respectively. At a first glimpse, these figures indicate that WRF-OL has generally higher FAR and POD indices for all scales and intensities throughout the year, with respect to COSMO-2I. This indicates that WRF-OL tends to produce rainfall events more frequently than COSMO-2I, resulting in higher probability of properly forecasting a rainfall event (Figs. 6 and 7), but also of forecasting events that do not actually occur (Figs. 4 and 6).

Also the seasonal behavior of FAR and POD indices confirms that the wrong localization of the precipitation event is responsible for the poor summer performances. In fact, similarly to what is observed for FSS, a significant difference is observed between summer and winter skills for small spatial scales, while smaller or absent seasonal variations are found at large spatial scales, even at high threshold intensities. This suggests that only when considering large verification areas the match between observed and simulated rainfall objects is accomplished. Once again, a degradation of the COSMO-2I performances in winter is detectable.

Figures 8 and 9 show the FSS indices (and the corresponding reliable scales) for the RUN2 of both models, on a seasonal basis. Other than the seasonal behavior observed for the RUN1 fuzzy logic analysis (poorer performances in summer for both WRF-OL and COSMO-2I, and poor performances in winter for COSMO-2I), the first thing to notice

a

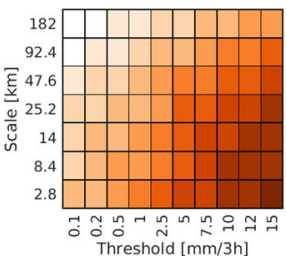

b

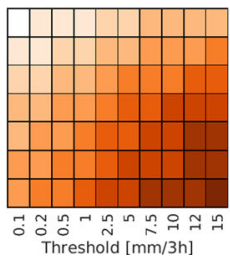

C

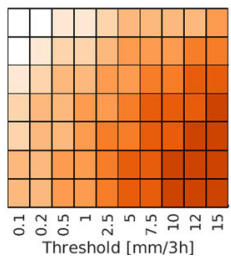

d

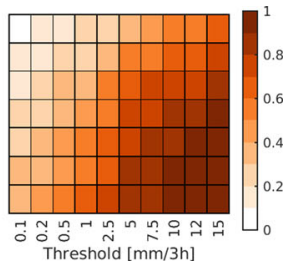

Fig. 5 Seasonal FAR scores for COSMO-2I RUN1 

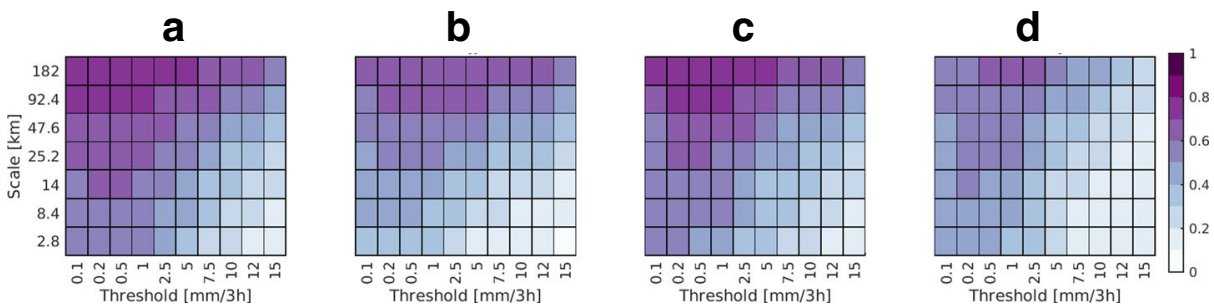

Fig. 6 Seasonal POD scores for WRF-OL RUN1

is that WRF-OL has a wider range of reliable spatial scales and rainfall thresholds with respect to COSMO-2I. This happens in all seasons, except for the moderate rainfall intensities at very large spatial scales in fall. In particular, in winter and spring, WRF-OL is found to produce reliable forecasts for moderate rainfall intensities at $O(50 \mathrm{~km})$ scales, whereas COSMO-2I is reliable at $O(100 \mathrm{~km})$ scales or beyond, in the same range of rainfall intensities. As expected, all performances for RUN2 are worse than those for RUN1.

\section{Conclusions}

CIMA runs the WRF model in the framework of the institutional cooperation with the Regional Agency for Environmental Protection of Liguria and the Italian Civil Protection Department. In particular, WRF is run at CIMA both for hydro-meteorological research and operational activities.

Using a fuzzy logic approach, the performances of a cloud-resolving WRF configuration, named WRF-OL, are evaluated and compared with another state-of-the-art operational model, COSMO-2I. Such an approach enables to avoid the well-know double penalty issue in the forecast verification, where small spatial mismatching between observations and forecasts produce large pointwise errors.

The fuzzy logic analysis proves that the convection-permitting WRF-OL setup is able to represent, with good accuracy, the weather conditions throughout the year. In fact, it produces reliable forecasts over the same ranges of combinations of spatial scales and rainfall intensities of the state-of-the-art operational COSMO-2I model (with slightly better performances in winter). This means that it can be fruitfully used as an operational tool, in the perspective to reduce the risk linked to natural phenomena involving harsh weather conditions.

a

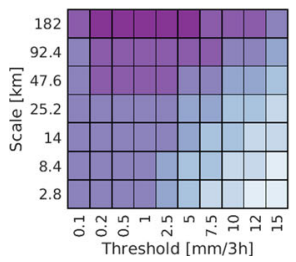

b

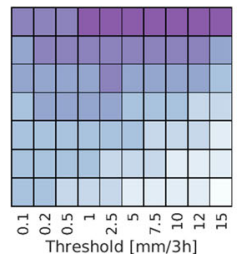

C

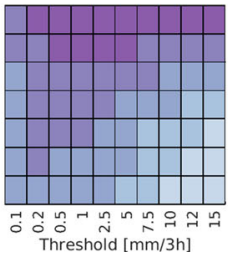

d

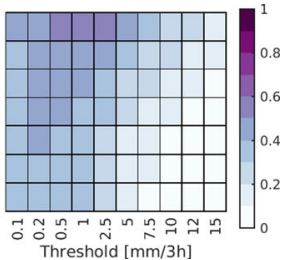

Fig. 7 Seasonal POD scores for COSMO-2I RUN1 
a

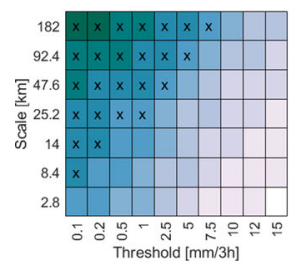

b

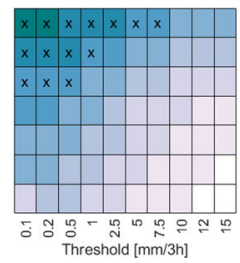

C

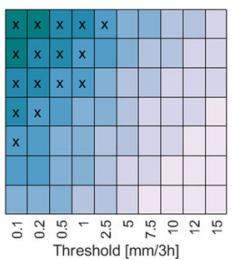

d

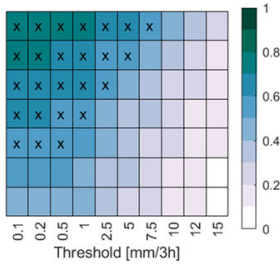

Fig. 8 Seasonal FSS scores for WRF-OL RUN2. "x" symbols denote useful FSS values

The skills of the model are tested in a range of spatial scales going from a few kilometers (namely, $2.8 \times 2.8 \mathrm{~km}^{2}$ ) to roughly $200 \times 200 \mathrm{~km}^{2}$, and accumulation precipitation thresholds from $0.1 \mathrm{~mm} / 3 \mathrm{~h}$ to $15 \mathrm{~mm} / 3 \mathrm{~h}$. Except for the combinations of high precipitation threshold and very small spatial scales, the model is able to reliably reproduce the weather phenomena for most of the year with reliable scales that get as fine as $10 \mathrm{~km}$ for light rains in spring, fall and winter, and as coarse as 100 or $200 \mathrm{~km}$ for heavy rains in summer. It is during summer that the predictive capabilities reach a minimum, especially in terms of rainfall localization. The low skills in summer, that are due to the nature of precipitation, i.e. mostly localized and convective, are a common feature of many NWP models (Oberto et al. 2012).

It emerges that WRF-OL tends to produce higher false alarms than COSMO-2I, but it also misses less events, having a higher probability of detection. COSMO-2I appears to underestimate the light precipitation events. This is in line with previous results that found similar behaviors with coarser grid-spacing of the same models (Oberto et al. 2012). Thus, it indicates that it is not the higher resolution that solves this kind of systematic errors, but the responsible has to be found among the numerical procedures of the codes, either in the equation formulation and approximations, or among the numerous physical schemes.

A degradation of the forecast skills is found from the first day of forecast to the second one. In particular, two runs of the model (with two different initialization) referring to the same verification time show remarkable differences: the RUN1, which has an initialization nearest to the time instant of interest is more skilful than the RUN2. In particular, the reliable scales of the two models are coarser in the RUN2 forecasts. WRF-OL, however, shows better skills with respect to COSMO-2I in all seasons and especially in winter and spring for moderate rainfall intensities.

Precipitation forecasts are affected by relatively high uncertainties, due to the inherent unpredictable nature of precipitation, which is particularly evident over the Italian territory, where the orographic features close to the coastlines, may generate very complex local weather conditions.

a

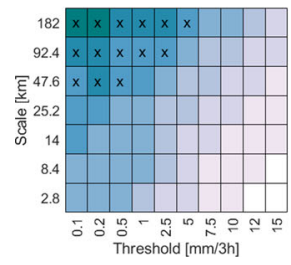

b

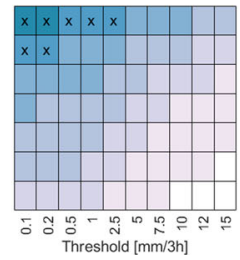

C

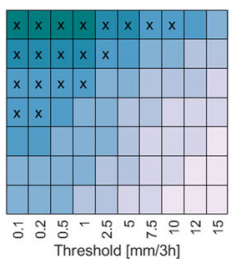

d

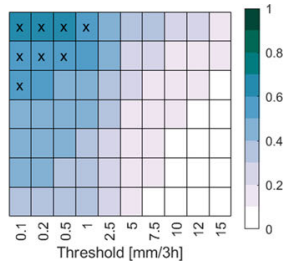

Fig. 9 Seasonal FSS scores for COSMO-2I RUN2. "x" symbols denote useful FSS values 
Future works will be devoted to validate the performances of a WRF operational configuration where radar reflectivity observations are assimilated to improve the model forecast capability, by means of 3DVAR data assimilation.

Acknowledgements A.N.M. acknowledges the TWIGA project, that has received funding from the European Union's Horizon 2020 Research and Innovation Programme under grant agreement no. 776691. A.P acknowledges CINECA and in particular Dr. Piero Lanucara for the technical support for the operational execution of WRF-OL.

Funding Open access funding provided by Università degli Studi di Genova within the CRUI-CARE Agreement.

\section{Declarations}

Conflict of interest The authors declare no competing interests.

Open Access This article is licensed under a Creative Commons Attribution 4.0 International License, which permits use, sharing, adaptation, distribution and reproduction in any medium or format, as long as you give appropriate credit to the original author(s) and the source, provide a link to the Creative Commons licence, and indicate if changes were made. The images or other third party material in this article are included in the article's Creative Commons licence, unless indicated otherwise in a credit line to the material. If material is not included in the article's Creative Commons licence and your intended use is not permitted by statutory regulation or exceeds the permitted use, you will need to obtain permission directly from the copyright holder. To view a copy of this licence, visit http://creativecommons.org/licenses/by/4.0/.

\section{References}

ARPAE (2020) COSMO 2I model setup. http://www.cosmo-model.org/content/tasks/operational/arpaesimc/default.htm. Accessed 01 June 2020

Baldauf M, Seifert A, Förstner J, Majewski D, Raschendorfer M, Reinhardt T (2011) Operational convectivescale numerical weather prediction with the COSMO model: Description sand sensitivities. Mon Weather Rev 139(12):3887-3905. https://doi.org/10.1175/MWR-D-10-05013.1

Barker D, Huang XY, Liu Z, Auligné T, Zhang X, Rugg S, Ajjaji R, Bourgeois A, Bray J, Chen Y et al (2012) The weather research and forecasting model's community variational/ensemble data assimilation system: WRFDA. Bull Amer Meteor Soc 93(6):831-843

Buzzi A, Davolio S, Malguzzi P, Drofa O, Mastrangelo D (2014) Heavy rainfall episodes over liguria in autumn 2011: numerical forecasting experiments. NHESS 14(5):1325-1340. https://doi.org/10.5194/ nhess-14-1325-2014

Capecchi V, Buizza R (2019) Reforecasting the flooding of florence of 4 november 1966 with global and regional ensembles. J Geophys Res Atmos 124(7):3743-3764. https://doi.org/10.1029/2018JD030231

Ebert EE (2008) Fuzzy verification of high-resolution gridded forecasts: a review and proposed framework. Meteor Appl 15(1):51-64. https://doi.org/10.1002/met.25

Ferraris L, Rudari R, Siccardi F (2002) The uncertainty in the prediction of flash floods in the northern mediterranean environment. J Hydrol 3(6):714-727

Fiori E, Comellas A, Molini L, Rebora N, Siccardi F, Gochis D, Tanelli S, Parodi A (2014) Analysis and hindcast simulations of an extreme rainfall event in the Mediterranean area: The Genoa 2011 case. Atmos Res 138:13-29

Fiori E, Ferraris L, Molini L, Siccardi F, Kranzlmueller D, Parodi A (2017) Triggering and evolution of a deep convective system in the Mediterranean Sea: Modelling and observations at a very fine scale. Q J R Meteor Soc 143(703):927-941. https://doi.org/10.1002/qj.2977

Giorgi F (2006) Climate change hot-spots. Geophys Res Lett 33(8):L08707. https://agupubs.onlinelibrary. wiley.com/doi/epdf/10.1029/2006GL025734

Han J, Pan HL (2011) Revision of convection and vertical diffusion schemes in the ncep global forecast system. Weather Forecast 26(4):520-533 
Hong SY, Noh Y, Dudhia J (2006) A new vertical diffusion package with an explicit treatment of entrainment processes. Mon Weather Rev 134(9):2318-2341

Iacono MJ, Mlawer EJ, Clough SA, Morcrette JJ (2000) Impact of an improved longwave radiation model, RRTM, on the energy budget and thermodynamic properties of the NCAR community climate model, CCM3. J Geophys Res Atmos 105(D11):14873-14890

Iacono MJ, Delamere JS, Mlawer EJ, Shephard MW, Clough SA, Collins WD (2008) Radiative forcing by long-lived greenhouse gases: Calculations with the AER radiative transfer models. J Geophys Res Atmos 113(D13):D13103. https://agupubs.onlinelibrary.wiley.com/doi/epdf/10.1029/2008JD009944

Lagasio M, Parodi A, Procopio R, Rachidi F, Fiori E (2017) Lightning Potential Index performances in multimicrophysical cloud-resolving simulations of a back-building mesoscale convective system: The Genoa 2014 event. J Geophys Res Atmos 122(8):4238-4257. https://doi.org/10.1002/2016JD026115

Lagasio M, Parodi A, Pulvirenti L, Meroni AN, Boni G, Pierdicca N, Marzano FS, Luini L, Venuti G, Realini E et al (2019a) A synergistic use of a high-resolution numerical weather prediction model and high-resolution earth observation products to improve precipitation forecast. Remote Sens 11(20):2387

Lagasio M, Pulvirenti L, Parodi A, Boni G, Pierdicca N, Venuti G, Realini E, Tagliaferro G, Barindelli S, Rommen B (2019b) Effect of the ingestion in the WRF model of different Sentinel-derived and GNSS-derived products: analysis of the forecasts of a high impact weather event. Eur J Remote Sens 52(sup4):16-33

Lagasio M, Silvestro F, Campo L, Parodi A (2019c) Predictive capability of a high-resolution hydrometeorological forecasting framework coupling WRF cycling 3dvar and Continuum. J Hydromet 20(7):1307-1337

Lagasio M, Meroni AN, Boni G, Pulvirenti L, Monti-Guarnieri A, Haagmans R, Hobbs S, Parodi A (2020) Meteorological osses for new zenith total delay observations: Impact assessment for the hydroterra geosynchronous satellite on the october 2019 genoa event. Remote Sens 12(22):3787

Llasat C, Siccardi F et al (2010a) A reflection about the social and technological aspects in flood risk management-the case of the Italian Civil Protection. Nat Hazards Earth Sys Sci 10(1):109-119. https://doi.org/10.5194/nhess-10-109-2010

Llasat MC, Llasat-Botija M, Prat MA, Porcu F, Price C, Mugnai A, Lagouvardos K, Kotroni V, Katsanos D, Michaelides S, Yair Y, Savvidou K, Nicolaides K (2010b) High-impact floods and flash floods in Mediterranean countries: the FLASH preliminary database. Adv Geos 23:47-55. https://doi.org/10.5194/adgeo-23-47-2010

Malguzzi P, Buzzi A, Drofa O (2011) The meteorological global model GLOBO at the ISAC-CNR of Italy assessment of $1.5 \mathrm{yr}$ of experimental use for medium-range weather forecasts. Weather and forecasting 26(6):1045-1055

Malguzzi P, Grossi G, Buzzi A, Ranzi R, Buizza R (2006) The 1966 "century" flood in Italy: A meteorological and hydrological revisitation. J Geophys Res, vol 111(D24106). https://doi.org/10.1029/2006JD007111

Mariani S, Casaioli M, Coraci E, Malguzzi P (2015) A new high-resolution BOLAM-MOLOCH suite for the SIMM forecasting system: assessment over two HyMeX intense observation periods. Nat Hazards Earth Sys Sci 15(1):1-24. https://doi.org/10.5194/nhess-15-1-2015

Marras I, Fiori E, Rossi L, Parodi A (2017) Effects of the representation of convection on the modelling of hurricane Tomas (2010). Adv Meteor, 2017. https://doi.org/10.1155/2017/1762137

Meroni AN, Renault L, Parodi A, Pasquero C (2018) Role of the oceanic vertical thermal structure in the modulation of heavy precipitations over the Ligurian Sea. Pure Appl Geophys 175:4111-4130. https://doi.org/10.1007/s00024-018-2002-y

Meroni AN, Montrasio M, Venuti G, Barindelli S, Mascitelli A, Manzoni M, Monti Guarnieri A, Gatti A, Lagasio M, Parodi A, Realini E, Tagliaferro G (2020) On the definition of the strategy to obtain absolute InSAR Zenith Total Delay maps for meteorological applications. Front Earth Sci 8:359. https://doi.org/10.3389/feart.2020.00359

Mlawer EJ, Taubman SJ, Brown PD, Iacono MJ, Clough SA (1997) Radiative transfer for inhomogeneous atmospheres: RRTM, a validated correlated-k model for the longwave. J Geophys Res Atmos 102(D14):16663-16682

Monti Guarnieri A, Rocca F (2017) Options for continuous radar Earth observations. Sci China Inform Sci 60(6):060301

Monti Guarnieri A, Leanza A, Recchia A, Tebaldini S, Venuti G (2018) Atmospheric phase screen in GEOSAR: Estimation and compensation. IEEE Trans Geosci Remote Sens 56(3):1668-1679

Oberto E, Milelli M, Pasi F, Gozzini B (2012) Intercomparison of two meteorological limited area models for quantitative precipitation forecast verification. Nat Hazards Earth Sys Sci 12:591-606. https://doi.org/10.5194/nhess-12-591-2012 
Parodi A, Tanelli S (2010) Influence of turbulence parameterizations on high-resolution numerical modeling of tropical convection observed during the TC4 field campaign. J Geophys Res Atmos 115(D10):D00J14. https://agupubs.onlinelibrary.wiley.com/doi/epdf/10.1029/2009JD013302

Parodi A, Boni G, Ferraris L, Siccardi F, Pagliara P, Trovatore E, Foufoula-Georgiou E, Kranzlmueller D (2012) The "perfect storm": From across the atlantic to the hills of Genoa. Eos Trans Am Geophy Union 93(24):225-226

Parodi A, Lagasio M, Maugeri M, Turato B, Gallus W (2019) Observational and modelling study of a major downburst event in Liguria: The 14 October 2016 case. Atmosphere 10(12):788

Peruccacci S, Brunetti MT, Gariano SL, Melillo M, Rossi M, Guzzetti F (2017) Rainfall thresholds for possible landslide occurrence in Italy. Geomorphology 290:39-57. https://doi.org/10.1016/j. geomorph.2017.03.031

Pignone F, Rebora N, Vulpiani G, Silvestro F, Castelli F (2013) RAINFUSION: A new method for combining radar and raingauge data. In: EGU general assembly conference abstracts, Vienna

Powers JG, Klemp JB, Skamarock WC, Davis CA, Dudhia J, Gill DO, Coen JL, Gochis DJ, Ahmadov R, Peckham SE et al (2017) The weather research and forecasting model: Overview, system efforts, and future directions. Bull Amer Meteor Soc 98(8):1717-1737

Reichenbach P, Cardinali M, De Vita P, Guzzetti F (1998) Regional hydrological thresholds for landslides and floods in the Tiber River Basin (central Italy). Env Geol 35(2-3):146-159

Roberts NM, Lean HW (2008) Scale-selective verification of rainfall accumulations from high-resolution forecasts of convective events. Mon Weather Rev 136:78-97. https://doi.org/10.1175/2007MWR2123.1

Ruiz Rodon J, Broquetas A, Monti Guarnieri A, Rocca F (2013) Geosynchronous SAR focusing with atmospheric phase screen retrieval and compensation. IEEE Trans Geosci Remote Sens 51(8):4397-4404

Schraff C, Reich H, Rhodin A, Schomburg A, Stephan K, Periáñez A, Potthast R (2016) Kilometrescale ensemble data assimilation for the cosmo model (kenda). QJRMS 142(696):1453-1472. https://doi.org/10.1002/qj.2748

Silvestro F, Rebora N, Rossi L, Dolia D, Gabellani S, Pignone F, Trasforini E, Rudari R, Angeli SD, Masciulli C (2016) What if the 25 october 2011 event that struck cinque terre (liguria) had happened in genoa, italy? flooding scenarios, hazard mapping and damage estimation. Nat. Hazards Earth Syst. Sci. 16(8):1737-1753

Silvestro F, Rossi L, Campo L, Parodi A, Fiori E, Rudari R, Ferraris L (2019) Impact-based flash-flood forecasting system: Sensitivity to high resolution numerical weather prediction systems and soil moisture. J Hydrol 572:388-402

Sinclair S, Pegram G (2005) Combining radar and rain gauge rainfall estimates using conditional merging. Atmos Sci Lett 6(1):19-22

Skamarock WC, Klemp JB, Dudhia J, Gill DO, Barker DM, Duda MG, Huang XY, Wang W, Powers JG (2008) A description of the advanced research WRF version 3. NCAR Tech Note NCAR/TN-475+STR, pp 113. https://doi.org/10.5065/D68S4MVH

Smirnova TG, Brown JM, Benjamin SG (1997) Performance of different soil model configurations in simulating ground surface temperature and surface fluxes. Mon Weather Rev 125:1870-1884

Smirnova TG, Brown JM, Benjamin SG, Kim D (2000) Parameterization of cold season processes in the maps land-surface scheme. J Geophys Res 105(D3):4077-4086

Tettamanti R, Malguzzi P, Zardi D (2002) Numerical simulation of katabatic winds with a non-hydrostatic meteorological model. Polar Atmosph 1:1-95

Trini Castelli S, Bisignano A, Donateo A, Landi TC, Martano P, Malguzzi P (2020) Evaluation of the turbulence parametrization in the moloch meteorological model. QJRMS 146(726):124-140. https://doi.org/10.1002/qj.3661

UK Met Office (2102) Fact sheet 3 - water in the atmosphere. https://www.metoffice.gov.uk/research/ library-and-archive/publications/factsheets

Viterbo F, von Hardenberg J, Provenzale A, Molini L, Parodi A, Sy O, Tanelli S (2016) High-resolution simulations of the 2010 Pakistan flood event: sensitivity to parameterizations and initialization time. J Hydromet 17(4):1147-1167

Vulpiani G, Pagliara P, Negri M, Rossi L, Gioia A, Giordano P, Alberoni PP, Cremonini R, Ferraris L, Marzano F (2008) The Italian radar network within the national early-warning system for multi-risks management. In: Proc. of fifth European conference on radar in meteorology and hydrology (ERAD 2008), Helsinki

Publisher's note Springer Nature remains neutral with regard to jurisdictional claims in published maps and institutional affiliations. 


\section{Affiliations}

\section{Apicella ${ }^{1,2} \cdot$ S. Puca ${ }^{3}$ - M. Lagasio ${ }^{2}$ A. N. Meroni ${ }^{2,4} \cdot$ M. Milelli' $^{2,5} \cdot$ N. Vela $^{5}$. V. Garbero ${ }^{5}$ - L. Ferraris ${ }^{2}$ - A. Parodi ${ }^{2,6}$}

L. Apicella

lorenza.apicella@ge.imati.cnr.it

S. Puca

silvia.puca@protezionecivile.it

M. Lagasio

martina.lagasio@cimafoundation.it

A. N. Meroni

agostino.meroni@cimafoundation.it

M. Milelli

massimo.milelli@arpa.piemonte.it

N. Vela

naimvela@arpa.piemonte.it

V. Garbero

valeria.garbero@arpa.piemonte.it

L. Ferraris

luca.ferraris@cimafoundation.it

1 National Research Council, Applied Mathematics and Information Technologies Institute, 16149, Genova, Italy

2 CIMA Research Fundation, 17100, Savona, Italy

3 Dipartimento Protezione Civile Nazionale Ufficio III-Attività Tecnico Scientifiche per la Previsione e Prevenzione dei Rischi, 00189, Rome, Italy

4 Department of Civil and Environmental Engineering, Politecnico di Milano, 20133, Milan, Italy

5 Regional Agency for Environmental Protection of Piedmont, 10135, Turin, Italy

6 Università degli Studi di Genova, Genova, Italy 